\title{
Geografías del trabajo en la nueva vitivinicultura. El caso de Valle de Uco, Mendoza
}

\section{Geographies of work in the new viticulture. The case of Valle de Uco, Mendoza}

Oscar Carballo

Doctor en Estudios Sociales Agrarios. Becario Posdoctoral del Consejo Nacional de Investigaciones Científicas y Técnicas CONICET. Instituto de Ciencias Humanas, Sociales y Ambientales INCIHUSA. Centro Científico Tecnológico CONICET Mendoza. Av. Ruiz Leal s/ $n$ Parque General San Martín, (5500) Mendoza, Argentina, oscar24oac@gmail.com, ORCID https://orcid.org/0000-0002-4407-6221

Juan Pablo Fili

Licenciado en Sociología. Becario doctoral del Consejo Nacional de Investigaciones Científicas y Técnicas CONICET. Departamento de Geografía. Facultad de Filosofía y Letras. Universidad Nacional de Cuyo. Centro Universitario, Parque San Martín s/n, (5502) Mendoza, Argentina, juanpablo_fili@yahoo.com, ORCID https://orcid.org/0000-0001-7672-3772

Anabella Ayelén Engelman

Geógrafa Profesional. Becaria doctoral del Consejo Nacional de Investigaciones Científicas y Técnicas CONICET. Instituto de Ciencias Humanas, Sociales y Ambientales INCIHUSA. Centro Científico Tecnológico CONICET Mendoza. Av. Ruiz Leal s/n Parque General San Martín, (5500) Mendoza, Argentina, anabellaengelman@gmail.com, ORCID https://orcid.org/0000-0002-0718-2762

Recibido: 20 de enero 2020 || Aprobado: 24 de agosto 2020

Resumen

La emergencia de la nueva vitivinicultura de exportación en el Valle de Uco a comienzos del presente siglo propició la aparición de un número de estudios que problematizaron la producción de espacio desde la categoría paisaje. No obstante, resulta imprescindible integrar a este análisis la trastienda del trabajo que hace posible tales paisajes, y el impacto sobre la vida cotidiana y las percepciones de los trabajadores. Para ello recurrimos a una aproximación desde la geografía del trabajo, la sociología del trabajo y la sociología rural. Desde un abordaje cualitativo, indagamos en las tensiones entre capital y trabajo subyacentes en el proceso de producción del paisaje. Como resultado destacamos las transformaciones materiales y espaciales en las formas de organización del trabajo que ha supuesto la nueva vitivinicultura y su impacto en la vida cotidiana de los trabajadores que la sustentan.

Palabras clave: Geografía del trabajo; Paisaje; Valle de Uco; Vitivinicultura

\section{Abstract}

The emergence of the new viticulture for export in the Uco Valley at the beginning of the present century led to the appearance of a number of studies that problematized the production of space from the landscape category. However, it is essential to integrate into this analysis the back room of the work that makes such landscapes possible, and the impact on the daily life and perceptions of the workers. For this, we appeal to an approach from the geography of work, the sociology of work and rural sociology. From a qualitative approach, we inquire into the tensions between capital and labor underlying the landscape production process. As a result, we highlight the material and spatial transformations in the forms of work organization that the new viticulture has brought about and its impact on the daily life of the workers who support it.

Key words: Geography of work; Landscape; Uco Valley; Viticulture

Cita sugerida: Carballo, O.; Fili, J.P. y Engelman, A.A. (2020). Geografías del trabajo en la nueva vitivinicultura. El caso de Valle de Uco, Mendoza. Estudios Socioterritoriales. Revista de Geografía, (28), 068. DOI: https://doi.org/10.37838/unicen/est.28-068 
INTRODUCCIÓN

¿Por qué el paisaje luce así (debido a que tiene una clara función
en su forma presente) y quién hace que luzca así?

(Mitchell, 1996, p. 5-6)

Este trabajo aborda un aspecto poco estudiado en el marco de las profundas transformaciones socioeconómicas que experimentó el Valle de Uco a partir de la última década del siglo XX. Numerosos estudios permitieron dar cuenta de las características de las transformaciones productivas, los cambios en la organización del trabajo, e incluso de los procesos de urbanización que acontecieron en el valle. Nuestro trabajo se apoya en esta rica producción y se propone contribuir a una línea de estudios relativamente recientes que agrupamos en lo que Thomaz Júnior (2002) denomina geografía del trabajo. A grandes rasgos esta línea indaga en torno a la imbricación de las formas históricas del trabajo y las construcciones particulares que surgen a partir de la producción social del espacio, no solo desde su materialidad sino también desde las subjetividades.

El primer apartado da cuenta de las reconfiguraciones históricas de la geografía del Valle de Uco a partir de sucesivas transformaciones productivas. El segundo apartado profundiza en las formas espaciales específicas que ocasionó la reconfiguración de la organización de trabajo con el modelo de la "nueva vitivinicultura" (Montaña, 2008, p. 3) a partir de la década del 2000. Por último, el tercer apartado busca comprender los desafíos espaciales que implica este último modelo sobre la reproducción social de la vida cotidiana de los trabajadores, y cómo ello genera subjetividades particulares. Para ello retomamos la noción de paisaje y su trastienda. Recurrimos a un diseño predominantemente cualitativo basado en entrevistas en profundidad, en combinación con el análisis documental y de diversas fuentes censales. El trabajo se basa en una larga trayectoria de los autores en la zona de estudio a lo largo de diferentes trabajos. Incluye una serie de 35 entrevistas realizadas en el periodo 2012-2018 a trabajadores agrícolas residentes en aglomeraciones del Valle de Uco como así también a referentes de la zona.

\section{CONFLUENCIAS TEÓRICAS HACIA UNA GEOGRAFÍA DEL TRABAJO}

El siguiente trabajo se propone seguir la línea abierta por las propuestas para una geografía del trabajo (Mitchell, 1996; Thomaz Júnior, 2002; entre otros), vinculando estos aportes a los desarrollos de la sociología del trabajo (De la Garza, 2011; Antunes, 2013; entre otros), y los estudios del trabajo de la sociología rural (Kay, 1997; Neiman, 2010; entre otros). Creemos que esta confluencia teórica nos proporciona las herramientas para comprender las profundas transformaciones del espacio rural en el área de estudio, y pretende además servir como aporte a una línea de investigación incipiente en nuestra región.

Partimos de la concepción de Lefebvre (2013) para quien cada sociedad produce sus espacios en cada coyuntura histórica. La naturaleza trialéctica del espacio nos permite adentrarnos en las contradicciones que forman parte intrínseca de las relaciones de producción y reproducción social. 
Este proceso histórico de producción social del espacio es para Lefebvre una secuencia comple$\mathrm{ja}$, a veces contradictoria, que entremezcla cuestiones relativas a las prácticas espaciales ${ }^{1}$ que de manera objetiva se dan en un determinado espacio, las representaciones simbólicas ${ }^{2}$ que se producen en torno a él o el imaginario social ${ }^{3}$ que genera (Baringo Ezquerra, 2013, p. 123-124) (notas al pie 1, 2 y 3 nuestras).

Mitchell (1996) incursiona en el análisis de estas contradicciones a través de la categoría de paisaje. Para el autor el paisaje es, por un lado, una poderosa ideología visual que funciona mitificando y justificando las relaciones de producción existentes; "pero es también una porción estructurada de la tierra en la que las personas trabajan, viven y duermen, comen, hacen el amor y luchan por sus condiciones de existencia" (Mitchell, 1996, p. 2). Es decir, paisaje como morfología y paisaje como representación.

El paisaje como categoría analítica, tradicionalmente ha sido reducido a lo visible, a aquello que es aparente ante los ojos del observador. De esta manera se suprime todo proceso social que se desarrolle a las sombras de las apariencias, entonces ¿cómo sería posible interpretar lo no visible? Mitchell (1996) otorga especial importancia a la categoría de paisaje, ya que esta reducción a lo observable permite ocultar el proceso de construcción y la historia del trabajo que hace posible ese paisaje. De esta forma, los trabajadores, con sus condiciones de vida y de trabajo quedan ocultos en su trastienda. $\mathrm{O}$, en el mejor de los casos, sirve para justificar esas condiciones con la magnificencia del paisaje colectivamente construido.

Es por esto que Mitchell propone una "teoría laboral del paisaje" (1996, p. 9), que no solo analice la morfología de una región sino que dé cuenta de la historia del trabajo que dio forma a la misma, de cómo las personas perciben y viven ese paisaje que construyen a diario; contribuyendo así a desmitificar la visión dominante que intenta imponerse. Además para Mitchell la categoría de paisaje nos permite apreciar que el mismo no solo es construido a partir de las relaciones de producción dominantes, sino que también la lucha por las condiciones de existencia de la clase trabajadora contribuye a crear la morfología de ese paisaje (Mitchell, 1996).

De esta forma, y retomando el marco teórico propuesto por Lefebvre (2013), podemos afirmar que la producción del espacio implica tanto prácticas espaciales como representaciones dominantes y subalternas, donde el espacio no solo es construido bajo las formas de producción dominantes, sino que también se construye a partir de la lucha cotidiana de los trabajadores por sus condiciones de existencia. Al mismo tiempo, estos trabajadores generan sus propias prácticas espaciales y representaciones sobre el espacio, apropiándose y resignificando el espacio de formas que a veces riñen y contradicen (en parte o totalmente) las representaciones y prácticas dominantes. Como

1 Prácticas espaciales (espacio percibido). Comprende "las relaciones sociales de producción y reproducción, en especial la división del trabajo, la interacción entre gente de diferentes grupos de edad y género, la procreación biológica de la familia y la provisión de la futura fuerza de trabajo. Incluye la producción material de las necesidades de la vida cotidiana (...) y el conocimiento acumulado por el que las sociedades transforman su ambiente construido" (Baringo Ezquerra, 2013, p. 124).

2 Representaciones del espacio (espacio concebido). "Conceptualizado por los "especialistas" -urbanistas, arquitectos, sociólogos, geógrafos o cualquier otra rama de la ciencia-, es el espacio dominante en las sociedades y está directamente ligado con las relaciones de producción existentes en una sociedad y al orden en el que estas relaciones se imponen" (Baringo Ezquerra, 2013, p. 124).

3 Espacio de representación (espacio vivido). "Es el espacio experimentado directamente por sus habitantes y usuarios a través de una compleja amalgama de símbolos e imágenes. Es un espacio que supera al espacio físico, ya que la gente hace un uso simbólico de los objetos que lo componen" (Baringo Ezquerra, 2013, p. 124). 
menciona Delgado (2013, p. 2) "En los espacios de representación puede encontrar uno expresiones de sumisión a códigos impuestos desde los poderes, pero también las expresiones del lado clandestino o subterráneo de la vida social”.

Este marco nos permite incorporar la dimensión geográfica a las profundas transformaciones ocurridas en el mundo del trabajo desde las dos últimas décadas del pasado siglo. En pleno auge neoliberal, desde la sociología del trabajo, comenzó a utilizarse el concepto de reestructuración productiva que daba cuenta de la profunda imbricación existente entre los cambios tecnológicos, la organización del trabajo y las relaciones laborales (De la Garza, 1993). Esta aproximación puso en evidencia que los fenómenos de reestructuración no se asentaron solo en un componente duro de cambio tecnológico, sino también en el desarrollo de estrategias empresariales que perseguían arrancar una mayor productividad al trabajo y una baja de los costos directos e indirectos de la contratación de fuerza de trabajo. El modelo de empresa flexible refuerza la adaptabilidad de la fuerza de trabajo a las condiciones fluctuantes y cambiantes de la demanda del mercado (Lara, 1992). Los principales efectos sobre el empleo fueron la aparición de nuevas y múltiples fragmentaciones generadas desde la demanda de trabajo, y un enorme crecimiento del trabajo precarizado (Antunes, 2013).

Si bien el trabajo rural nunca se caracterizó por el modelo típico fordista, es decir un trabajo estable, de tiempo completo y con seguridad social (De la Garza, 2011), la reestructuración neoliberal ocasionó algunos cambios notorios. Entre ellos podemos mencionar la combinación de crecientes requerimientos de calificaciones y de competencias, en paralelo a la profundización de la precariedad laboral, creciente residencia urbana y multiocupación de los trabajadores (Neiman, 2010). Estos fenómenos se desarrollaron en el contexto de una acelerada concentración empresarial. La adopción de ciertas tecnologías impulsaron la reorganización de los procesos de trabajo, pero además las empresas desarrollaron estrategias de contratación aún más estacionalizadas de lo que el ciclo productivo lo indicaría (Fabio, 2006); a tal punto que las grandes empresas son las mayores demandantes de fuerza de trabajo transitorio (Neiman, Bardomas y Quaranta, 2003). Por otro lado, el abandono de un marco favorable al desarrollo del mercado interno dejó a una importante cantidad de pequeños y medianos productores sin un sustento de políticas que apuntalaran su reproducción (Rubio, 2001). La desaparición de miles de estas explotaciones tuvo un papel importante en la reconfiguración de la oferta de fuerza de trabajo, ya que las mismas cumplían un papel de reserva de fuerza de trabajo para el agro (Aparicio y Benencia, 1999).

En este trabajo nos proponemos dar cuenta de las transformaciones espaciales que implicó la mencionada reconfiguración del trabajo agrario y cómo este conjunto impactó sobre la vida cotidiana de los trabajadores, como así también de las prácticas y percepciones que estos últimos generan en la lucha por sus condiciones de existencia.

\section{LA CONFORMACIÓN HISTÓRICA DEL VALLE DE UCO COMO ESPACIO PRODUCTIVO}

Como planteamos en el epígrafe de este artículo nos propusimos problematizar sobre las razones por las que el paisaje luce como luce. Es decir, indagar sobre la producción histórica del paisaje. Mitchell señala que

la continua lucha de parte del capital para hallar una forma para que la fuerza de trabajo sea propiamente reproducida y la continua lucha de parte de los trabajadores para resistir la constante cosificación y marginalización, son las que hacen y estructuran la tierra. (Mitchell, 1996, p. 11). 
Con ello el autor reafirma la constante tensión entre el capital y el trabajo en la producción del paisaje.

El Valle de Uco es uno de los tres grandes oasis productivos de la provincia de Mendoza. Asentado sobre la cuenca del Río Tunuyán Superior, comprende una superficie irrigada de aproximadamente 47.000 ha (INDEC, 2008) situadas en los departamentos de Tupungato, Tunuyán y San Carlos. En líneas generales puede afirmarse que este oasis presenta una historia productiva que lo diferencia de modo significativo de las trayectorias del oasis norte y sur de la provincia.

Bajo el dominio español se destaca el acople de estos territorios con Chile como proveedores de fuerza de trabajo indígena, para luego, a partir del siglo XVII, formar parte de los intercambios agrícolas y ganaderos que fueron de gran importancia en el desarrollo de la economía de Cuyo (Lacoste, 1997).

A partir de la etapa independentista, los circuitos comerciales en los que se insertaba la provincia de Mendoza sufrieron una fuerte desarticulación, lo cual sumado al cambio de metrópoli generaron un fuerte desequilibrio comercial (Bragoni, 2004). Ante esta realidad, las élites locales encontraron en el comercio de ganado a Chile una alternativa muy atractiva (Fili y Engelman, 2020). El desplazamiento en Chile de la ganadería por el cultivo de cereales ocasionado por la fiebre del oro en California, proporcionó la oportunidad para el desarrollo del modelo ganadero entre 1850 y 1880 en la provincia (Richard Jorba, 1998). Mendoza se convirtió en lugar de tránsito para el ganado en pie proveniente principalmente del sur de Córdoba con destino a Chile. Así se extendieron los cultivos de alfalfa para alimentar al ganado en tránsito.

En el Valle de Uco surgieron grandes estancias que aseguraban el cruce por los pasos más meridionales. Allí "pequeñas manchas cultivadas se desarrollaban en torno de asentamientos militares (San Carlos) y estancias" (Richard Jorba, 1998, p. 44). La producción para ese entonces mostraba una clara especialización en el cultivo de alfalfa-cereales. El censo de 1869 daba cuenta de solo 6.181 habitantes en Valle de Uco ${ }^{4}$. En el campo, el trabajo quedaba bajo supervisión de mayordomos y capataces, a menudo en haciendas organizadas como núcleos cerrados autosuficientes. La mayor demanda de trabajo estacional del verano se cubría con la proletarización forzada apoyada en la obligatoriedad de portación de papeleta de conchabo 5 (Richard Jorba, 2000).

La llegada del ferrocarril a Mendoza en 1885 y el progresivo aumento de los gravámenes al ingreso de ganado en Chile pusieron fin al modelo ganadero (Collado, 2006). En reemplazo, la vitivinicultura se convirtió en la principal actividad económica de la provincia, aunque inicialmente se desarrolló casi exclusivamente en los oasis norte y sur. El Valle de Uco quedó al margen de esta transformación, sufriendo un considerable estancamiento económico y poblacional. No fue sino hasta 1911 que el ferrocarril llegó a Tunuyán y en 1923 a Eugenio Bustos en San Carlos (Delgado, 2004), solo dos décadas antes de la crisis del '29 y las primeras erradicaciones de viñedos. Este hecho favoreció el desarrollo de un perfil productivo bastante diversificado.

A partir de la llegada del ferrocarril el valle experimentó una tardía reconversión. Con el progresivo arribo de inmigrantes europeos se fue expandiendo la superficie cultivada (Saldi y Petz, 2015). La construcción del dique Valle de Uco en 1941 dio origen

4 Para un total de 65.413 habitantes en la provincia de Mendoza (MI, 1869).

5 La obligación de la portación de la papeleta de conchabo para la población criolla no fue abolida sino hasta 1900 (Salvatore, 1986). 
a la que sería la principal zona de cultivos hasta la mitad del siglo XX, ubicada al oeste del eje Tunuyán-San Carlos. Hacia 1937 los cultivos de granos, cereales y forrajes aún ocupaban más de la mitad de la superficie cultivada sumando más de 16.000 ha, pero seguidos de cerca por una diversidad de otros cultivos ${ }^{6}$. Los datos del censo de 1960 (IIET, 1962) permiten apreciar la magnitud de tal reconversión, en orden de importancia según las superficies sembradas figuraban el cultivo de vid (12.066 ha), forrajes (8.735 ha), frutales (8.701 ha), hortalizas (8.568 ha), granos y cereales (2.670 ha) y más de 11.000 .000 de plantas forestales.

Durante este periodo la población casi se triplicó pasando de 13.873 habitantes en 1914 a 37.826 en 1947 (DNSE, 1947). Inchauspe destacaba la considerable densidad de población ${ }^{7}$ en una región con solo dos centros poblados con más de 6.000 habitantes, Tunuyán y La Consulta. La población de las zonas agrícolas se agrupaba en torno a los caminos rurales conformando "nutridas poblaciones lineales" (Inchauspe, 1957, p. 138). En general los centros urbanos y caseríos rurales dispersos tradicionales se vincularon a ríos e importantes arroyos ${ }^{8}$. Según Velasco (1963) la ubicación de las casas quedaba determinada por la cercanía a la hijuela de riego. La misma autora describe el patrón de asentamiento de la población rural en la provincia por su hábitat disperso y una aglomeración intercalar. "Se forma un villorrio o caserío a posteriori, cuando alineadas sobre una ruta principal se han acercado varias casas de campesinos y un almacén u otro comercio de aprovisionamiento aprovechan los cruces de caminos para instalarse en las esquinas" (Velasco, 1963, p. 50).

Durante esta etapa la tenencia de la tierra en la zona irrigada del Valle de Uco se caracterizó por una importante subdivisión ${ }^{9}$. Esta tendencia comenzó a revertirse a partir de la expansión que experimentó el oasis desde mediados de la década de 1960 en base a la explotación de aguas subterráneas. La electrificación rural y una serie de políticas de desgravación impositiva destinadas a la expansión de las zonas irrigadas impulsaron una renovada especulación sobre las tierras rurales. Roncelli (1969) documenta la subdivisión de un área de 14.500 ha en los distritos de Cordón del Plata y El Zampalito en Tupungato. Allí tres antiguas propiedades fueron fraccionadas, acondicionadas y puestas en venta, principalmente en grandes propiedades. Como se observa en el Mapa 1, esta forma de expansión ${ }^{10}$ también se repitió en menor escala en otras zonas del Valle de Uco, en particular hacia el oeste del oasis de riego tradicional hasta la traza de la Ruta Provincial No 89 (Larsimont, 2018).

6 El censo de 1937 da cuenta de 9.782 ha de granos y cereales, 6.604 ha forrajes, 7.247 ha de hortalizas, 4.352 ha de vid, y 2.011 ha de frutales. Además, se mencionan unas 4.000.000 de plantas forestales en 1943 (IIET, 1962).

7120 habitantes por $\mathrm{km}^{2}$.

8 La ciudad de Tunuyán ha crecido junto al río homónimo además de confluir en él otros arroyos menores, al igual que la ciudad de Tupungato goza de la cercanía del arroyo del Peral con el Chupasangral. Por su parte la Villa de San Carlos se erigió en la confluencia del arroyo Yaucha y el Aguanda.

9 A modo de ejemplo, el censo agropecuario de 1960, da cuenta de 882 viñedos en Valle de Uco, de los cuales 709 poseían hasta 16 ha de vid, 144 entre 16 y 50 ha y 29 explotaciones poseían más de 50 ha con viñedos (IIET, 1962). 10 Según el Censo Agropecuario del Valle de Uco de 1979, de las 201 EAP con más de 50 ha cultivadas, 66 regaban solo con agua subterránea, 53 solo con agua superficial, 70 con riego mixto y 12 sin determinar (DA, 1979). 
Mapa 1. Ampliación del oasis de riego en Valle de Uco 1957-2019

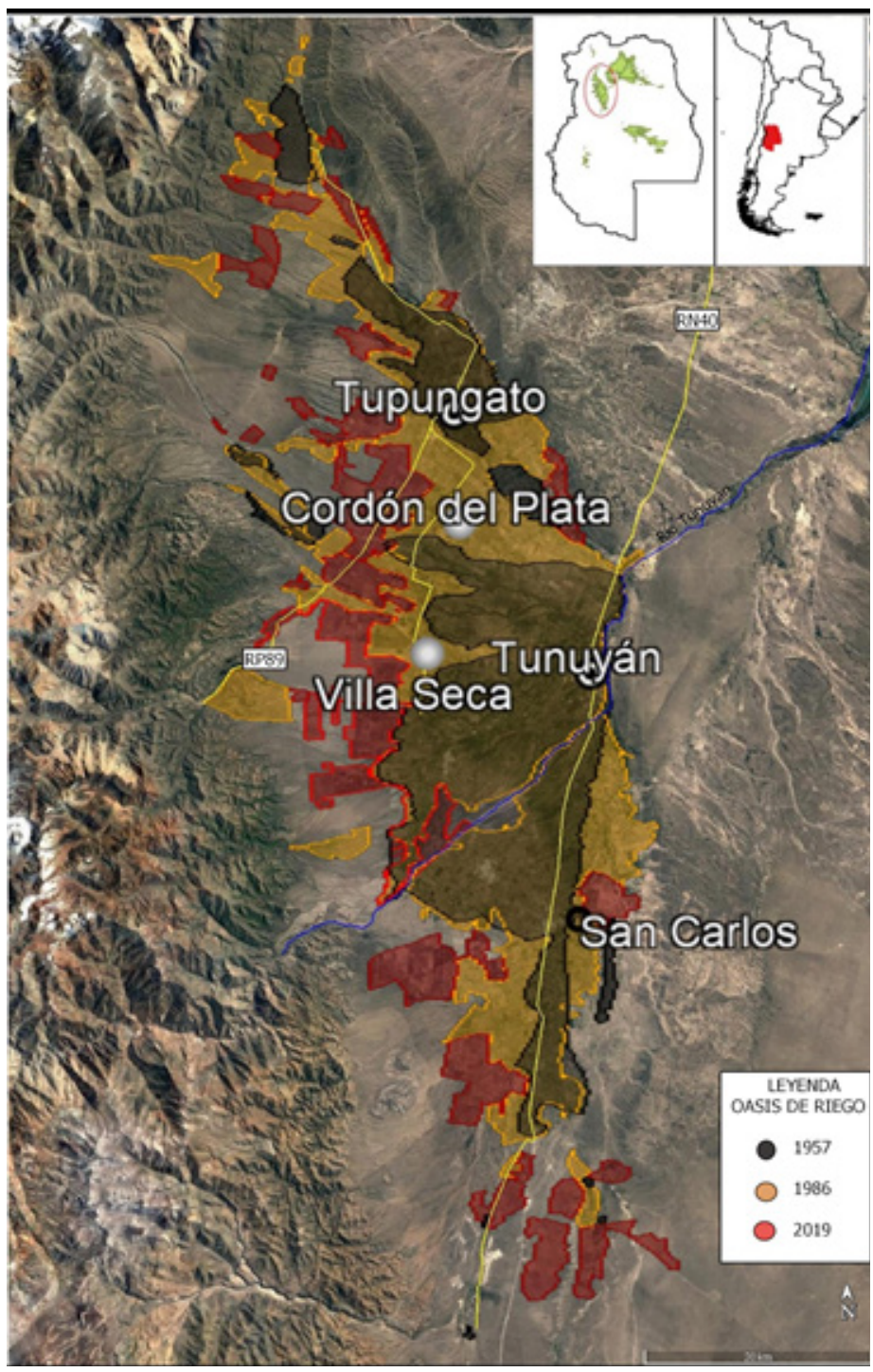

Fuente: elaboración personal con base en Inchauspe (1957), imagen satelital Landsat 1986, imagen Landsat Google Earth 2019. Año 2020

Más allá del crecimiento de la mediana y gran explotación agropecuaria, el proceso de trabajo agrícola no sufrió grandes transformaciones. La necesidad de efectuar el riego periódico se mantuvo como la base del trabajo permanente, al cual también se le asignaban resto de las labores de mantenimiento de los cultivos. De este modo, ya fuera en una explotación de tipo familiar, u organizada con trabajo asalariado o bajo contrato $^{11}$, esta organización del trabajo favorecía la residencia del trabajador y su familia en la explotación. La capacidad de trabajo limitaba la superficie a cargo de una persona y su

11 La forma habitual de contratación en el cultivo de la vid se hacía bajo la figura del contratista de viñas y frutales. El contratista recibe a su cargo una determinada superficie por la cual obtiene una suma mensual y un porcentaje de la cosecha, además de una vivienda en la explotación. Este trabajador no solo aporta su fuerza de trabajo sino también, habitualmente, la de su grupo familiar. En cultivos hortícolas por lo general la organización del trabajo se basa en la aparcería. La forma de aparcería más difundida en Mendoza es aquella en la cual el aparcero solo aporta el trabajo, por el cual obtiene entre el $25-30 \%$ de la producción. Las condiciones de dichos acuerdos se asemejan más a una forma de trabajo precarizado encubierto que a un acuerdo entre sujetos similares (Carballo e Ivars, 2018). 
familia, como mucho, a unas 10 ha. La demanda de trabajo adicional, como en periodo de cosecha, se resolvía en gran medida con la población local -en la cual el minifundio jugaba un papel importante- $y$ con migrantes temporarios (Sabalain y Reboratti, 1980).

\section{HUELLAS MATERIALES DE LA ORGANIZACIÓN DEL TRABAJO}

A partir de la segunda mitad de la década de 1970 comenzó a desbaratarse el modelo de "desarrollo agroindustrial con integración de la agricultura familiar" (Giarraca y Teubal, 2017, p. 350) característico de la etapa de sustitución de importaciones. Los cultivos destinados al mercado interno fueron sufriendo una serie de duros golpes y profundas reestructuraciones. La caída del consumo a nivel nacional confluyó con un récord de la superficie implantada. A principios de la década de 1980 sobrevino una de las crisis más agudas de la vitivinicultura mendocina. En tan solo una década se pasó de una fuerte política de regulación y fomento a la extensión de variedades para el consumo interno, a una progresiva desregulación y reorientación de la política hacia la exportación. Durante esa década la superficie con vid se retrajo casi 100.000 ha en toda la provincia ${ }^{12}$, en el Valle de Uco pasó de 18.711 ha en 1979 a 9.355 ha en 1988 (DA, 1979; INDEC, 1988).

Las políticas de apertura y desregulación económica de la década de 1990 iniciaron una intensa transformación en la estructura agraria del Valle de Uco. El ejemplo más notable fue la instalación de los emprendimientos de la llamada "nueva vitivinicultura" (Montaña, 2008, p. 3) orientada a la exportación. Estos últimos se ubicaron en la zona del piedemonte, al oeste de la Ruta Provincial № 89; zona que había permanecido, salvo algunas excepciones, sin cultivar y por ende con una escasa subdivisión. El bajo costo inicial de estas tierras junto a la posibilidad económica y técnica para ponerlas en producción atrajo a importantes capitales tanto nacionales como extranjeros.

Otro de los cultivos que proliferó fue el ajo destinado a la exportación, el cual lideró un considerable proceso de concentración en la producción hortícola (Carballo, 2019). En contraste, otros cultivos históricos del Valle de Uco sufrieron importantes retrocesos, como el tomate para industria y los frutales de pepita -manzana y pera-. El primero sufrió una fuerte reducción de las superficies sembradas durante la década de 1990. A partir de allí se desarrolló una profunda reestructuración de la actividad adoptando un modelo de integración vertical intensivo en insumos y maquinaria, al mismo tiempo que se produjo un desplazamiento espacial hacia el oasis norte. En tanto los cultivos de manzana y pera experimentaron un continuo declinar que se ha acelerado en la última década, a tono con la crisis que experimenta el sector a nivel nacional (IDR, 2018).

Estos fenómenos siguieron un patrón espacial bastante definido:

El sector alto (especialmente de Tupungato y Tunuyán) ha sido colonizado por importantes emprendimientos vitivinícolas que avanzaron sobre el piedemonte extendiendo la frontera irrigada siendo su producción de uvas finas la más reconocida. (...) El sector medio y bajo del Valle, especialmente en Tunuyán dedicado a la fruticultura de pepitas y al tomate con destino a envasado ha sufrido un proceso dramático de regresión. El paisaje de la Ruta $N^{\circ} 40$ presenta un ambiente de propiedades abandonadas o envejecidas. (Van den Bosch, 2008a, p. 75)

En la Tabla 1 podemos apreciar la magnitud de estas transformaciones. Solo entre el periodo 2002-2008 salieron de producción 990 explotaciones de menos de 50,1 ha, es decir una reducción del $32 \%$ en solo seis años. En términos de superficie implicó

12 En 1978 se llegó a un máximo de 253.000 ha de vid implantadas en la provincia. En 1988 esa cantidad se había retraído a 157.000 ha (Richard-Jorba, 2008; INDEC, 1988). 
una disminución del 26\% para los tres estratos inferiores. En contraste el estrato superior evidenció un incremento del $12 \%$ en el número de explotaciones y aún mayor (21\%) en el área cultivada.

Tabla 1. Cantidad de EAP y superficie cultivada (en ha) por estratos según superficie cultivada total. Valle de Uco. Años 2002 y 2008

\begin{tabular}{l|r|r|r|r|r|r|}
\hline & \multicolumn{2}{c}{ CNA 2002} & \multicolumn{2}{c}{ CNA 2008 } & \multicolumn{2}{c|}{ Variación Absoluta } \\
\cline { 2 - 8 } & EAPs & $\begin{array}{l}\text { Ha cul- } \\
\text { tivadas }\end{array}$ & EAPs & $\begin{array}{l}\text { Ha cul- } \\
\text { tivadas }\end{array}$ & EAPs & \multicolumn{1}{c|}{$\begin{array}{l}\text { Ha cul- } \\
\text { tivadas }\end{array}$} \\
\hline Hasta 5 ha & 1.744 & 2.836 & 1.087 & 1.607 & -657 & -1.229 \\
\hline 5,1 a 18 ha & 844 & 8.555 & 636 & 6.718 & -208 & -1.838 \\
\hline 18,1 a 50 ha & 487 & 14.818 & 362 & 11.061 & -125 & -3.757 \\
\hline Más 50 ha & 197 & 22.775 & 221 & 27.583 & 24 & 4.807 \\
\hline Total & 3.272 & 48.985 & 2.306 & 46.969 & -966 & -2.016 \\
\hline
\end{tabular}

Fuente: elaboración personal con base en datos del Censo Nacional Agropecuario (2002; 2008)

Las grandes empresas de la nueva vitivinicultura introdujeron transformaciones significativas en la organización del trabajo. El cambio más importante ocurrió a partir de la adopción de sistemas de riego presurizados. Este tipo de riego permitió eliminar la tarea que había constituido la base de la organización del trabajo agrícola permanente en la provincia. "Con un sistema de riego mecanizado con riego presurizado vos regás 200, 300 ha con una sola persona; y ya con otras capacidades, no es un obrero de campo, sino que a veces es más un técnico" (E1, agrónomo, 55-60 años).

A partir de este momento la mayoría de las tareas de mantenimiento de los cultivos pudieron organizarse con trabajadores transitorios. Este cambio fue la base de lo que Fabio describe como una mayor "estacionalización" (2006, p. 4) de las labores agrícolas. Es decir la organización del trabajo en base a personal temporario, buscando una estacionalidad incluso por encima de lo que el ciclo productivo del cultivo demandaría. Estas estrategias responden a "comportamientos destinados a reducir costos, simplificar la organización y control del trabajo, eludir compromisos vinculados a la legislación laboral o desdibujar el vínculo laboral entre empleadores y trabajadores" (Fabio, 2006, p. 4). Un encargado de finca de una empresa con 100 ha y solo cuatro empleados permanentes comentó:

Este año la mayoría del trabajo se hizo todo con un empresa de servicios (...) nos trae toda la gente, para lo que nos haga falta, lo que es cosecha, todo (...) Si tengo que sacar una maleza de los ajos, viene la gente que trabaja en cuadrillas, vienen dos días y se van. (E2, encargado de finca, 35-40 años)

La eliminación de la tarea del riego también permitió reducir al mínimo la cantidad de personas residentes en la explotación. Un entrevistado comentó: "para la empresa tener gente adentro del predio es un riesgo" (E1, agrónomo, 55-60 años). En la misma dirección otro entrevistado agregó:

Dentro de la finca no hay ni un viviente, ni el encargado. Tienen guardias para dejar cuando se va toda la gente, pero vivientes nadie. Y antes todo eso eran casas, usted sabe las casas que había en La Celia. Las voltearon todas. (E3, obrero agrícola, 70-75 años)

Sin embargo, esta situación no debe generalizarse al resto de las explotaciones. En las explotaciones pequeñas (menos de 15 ha cultivadas) que se sostienen principalmente con fuerza de trabajo familiar, la explotación sigue siendo el lugar de residencia. Una situación similar se encuentra en las explotaciones de tamaño intermedio (entre 15 y 50 ha cultivadas), en ellas a menudo alguno o todos los trabajadores permanentes residen 
en la explotación. Más aún, entre los productores medianos aparecen prácticas que buscan fidelizar un cierto número de trabajadores a través de la vivienda; frente a la escasez de trabajadores que ocasiona la fuerte demanda de trabajo temporario de las grandes empresas en época de cosecha.

Si vos tenés que cosechar con la gente de acá no levantás cosecha. Ya nos pasó un año que trabajamos con cuadrilleros (...) por ahí un lunes te salían dos personas y el miércoles tenías quince, entonces tardás tres días para Ilenar un camión, es muy jodido. Vos cuando traes gente de afuera sabes que el tucumano va a estar, todo el día, todos los días, y son guapos. (E4, productor, 29 años)

Si observamos la Tabla 2 podemos apreciar una reducción de 6.351 residentes en las explotaciones en Valle de Uco en el periodo 2002-2008. Esto ocurrió en un contexto de un crecimiento demográfico del Valle de Uco superior al promedio provincial ${ }^{13}$ y de un incremento de la población ocupada en el sector agropecuario, que pasó de 12.874 a 14.472 en el periodo 2001-2010 en el valle (INDEC, 2001; 2010). La tabla permite apreciar que los tres primeros estratos dan cuenta del $89 \%$ de dicha reducción. Ello se explica en parte debido a la importante desaparición de explotaciones. Sin embargo, si analizamos el fenómeno por estratos, observamos que en las explotaciones de hasta 5 ha cultivadas la expulsión se da por igual entre el productor y su familia como entre 'otros residentes'. En cambio, en los dos estratos intermedios la expulsión se produce casi exclusivamente en la categoría de 'otros residentes', siendo esta última categoría representativa principalmente de las familias de los trabajadores. En el estrato superior se produce una reducción moderada en el total de personas que residen en la explotación, aún a pesar del aumento del número de explotaciones. La reducción más fuerte ocurre en la categoría 'otros residentes' al mismo tiempo que se observa un ligero aumento entre los 'trabajadores no familiares'.

Tabla 2. Residentes en la explotación. Valle de Uco. Años 2002 y 2008

\begin{tabular}{|c|c|c|c|c|c|c|c|c|c|c|}
\hline & \multicolumn{2}{|c|}{ Productor } & \multicolumn{2}{|c|}{$\begin{array}{l}\text { Familiar del } \\
\text { productor }\end{array}$} & \multicolumn{2}{|c|}{$\begin{array}{l}\text { Trabajador } \\
\text { no familiar }\end{array}$} & \multicolumn{2}{|c|}{$\begin{array}{l}\text { Otros re- } \\
\text { sidentes }\end{array}$} & \multicolumn{2}{|c|}{ Subtotal } \\
\hline & 2002 & 2008 & 2002 & 2008 & 2002 & 2008 & 2002 & 2008 & 2002 & 2008 \\
\hline Hasta 5 ha & 774 & 570 & 2.257 & 1.051 & 238 & 206 & 1.732 & 510 & 5.001 & 2.337 \\
\hline 5,1 a 18 ha & 246 & 296 & 735 & 563 & 580 & 606 & 2.356 & 1.003 & 3.917 & 2.468 \\
\hline 18,1 a 50 ha & 116 & 121 & 331 & 329 & 791 & 836 & 2.744 & 1.149 & 3.982 & 2.435 \\
\hline Más 50 ha & 37 & 50 & 114 & 143 & 973 & 1.334 & 2.624 & 1.530 & 3.748 & 3.057 \\
\hline Subtotal & 1.173 & 1.037 & 3.437 & 2.086 & 2.582 & 2.982 & 9.456 & 4.192 & 16.648 & 10.297 \\
\hline
\end{tabular}

Fuente: elaboración personal con base en datos del Censo Nacional Agropecuario (2002; 2008)

Las dinámicas señaladas contribuyeron al incremento de la residencia de los trabajadores agropecuarios en zonas urbanas o en aglomeraciones ubicadas en zonas rurales. Furlani, Gutiérrez, Molina y Lotfi (2000) identificaban dos procesos de crecimiento de los asentamientos poblacionales en el Valle de Uco: por un lado, el "crecimiento por barrios discontinuos en la periferia de los centros urbanos mayores ya existentes” (p. 2); y por otro lado, la construcción de "barrios rurales en lugares más o menos aislados, que generan

13 La población en los tres departamentos del Valle de Uco creció un 15,8\% en el periodo 2001-2010, pasando de 99.005 a 114.613 habitantes. En comparación, el incremento para el total de población de la provincia fue de 10,1 en igual periodo (INDEC, 2001; 2010). 
nuevos asentamiento poblacionales" (p. 2). El primero de ellos contribuyó al crecimiento, tanto de los centros urbanos de mayor jerarquía como Tunuyán, Tupungato y La Consulta; como de centros de jerarquía intermedia como San José, Villa Bastías y Cordón del Plata en Tupungato, Colonia Las Rosas y Los Sauces en Tunuyán, y Pareditas y Chilecito en San Carlos. Los nuevos barrios se ubicaron en "zonas periféricas de las ciudades, en forma discontinua y casi siempre invadiendo áreas rurales" (Martínez, de la Rosa, Suortino, Gómez y Castro, 1999, p. 102). En tanto el segundo proceso dio origen a nuevos asentamientos en parajes de menos de 200 habitantes en los tres departamentos (Martínez et. al, 1999). Según una encuesta realizada en 40 de estos nuevos barrios construidos a partir de la década de 1990 en Valle de Uco, la amplia mayoría de la población económicamente activa (73\%) de los mismos se dedicaba a labores agrícolas (Molina, 1999).

Como menciona Rau (2009) muchos barrios periurbanos se convirtieron en el lugar físico donde operan los mercados de trabajo agropecuario transitorio. Allí se lleva a cabo el reclutamiento diario de trabajadores que se distribuyen por numerosas explotaciones en todo el valle. Además algunos de estos barrios constituyen espacios articuladores entre la demanda de fuerza de trabajo característica de la época de cosecha y los importantes contingentes de migrantes temporarios que arriban cada temporada a la zona (Moreno, 2019). Un obrero del B El Esfuerzo de San Carlos comentó:

Lo que pasa es que como acá hay muchos cuadrilleros, entonces al haber cuadrilleros ya corre la información o te vienen a ver, porque un tiempo que también la gente se va, mucha gente que viene golondrina, del norte, llega un momento que se termina la cosecha y se empiezan a ir. (E5, obrero agrícola, 20-25 años)

Durante un tiempo era común que los migrantes temporarios se alojaran "simplemente [en] un campamento de carpas, donde conviven durante todo el verano sin agua potable ni servicios sanitarios" (Van den Bosch, 2008b, p. 126). A raíz de la mayor presencia de controles por parte del Estado en la zona, este tipo de alojamiento disminuyó, aunque se siguen utilizando fincas adentro donde resulta más difícil localizarlos. A partir de allí comenzaron a incrementarse en algunos barrios, alojamientos llamados popularmente colectivas $^{14}$, donde se alojan los trabajadores temporarios. Un entrevistado comentó:

hay gente de acá de la zona que tiene cuadrillas, que tienen casa para alquilar o sea tienen piezas que alquilan y viene gente a alquilary trabajan para ellos. Acá hay un muchacho salteño que tiene una tipo "colectiva", se ha comprado los vehículos, ha hecho unas "colectivas" así y toda la temporada vienen los tucumanos, les da donde viviry trabajan con él. (E6, obrero agrícola, 45-50 años)

El crecimiento de la actividad agrícola en Valle de Uco motivó el asentamiento permanente de muchos de los inmigrantes, particularmente en Tupungato. Este departamento muestra el porcentaje más alto en la provincia de población nacida en el extranjero, que llega a 7,7\%, de los cuales 8 de cada 10 son procedentes de Bolivia. En comparación, este porcentaje solo alcanza el 3,6\% para toda la provincia (Pol, Fresia y Romero, 2015). En esta dinámica se formaron algunos barrios donde predomina la población de este origen. Una obrera de Cordón del Plata mencionó sobre un sector del pueblo conocido como Loteo Bazán: "Todo eso es de paisanos (inmigrantes bolivianos) así que vos vas a ver una casa y en esa casa jviven 50! Muchísima gente, y muchos alquileres sé que hay para allá. Potosí le dicen" (E8, obrera agrícola, 35-40 años).

14 Este término hace referencia a un conjunto muy heterogéneo de espacios destinados al alojamiento de obreros temporarios. La misma puede comprender espacios continuos con divisiones temporarias de todo tipo (lonas, maderas, etc.) o pequeñas piezas, todas con espacios de uso común como baño y cocina. 


\section{PAISAJE Y VIDA COTIDIANA DE LOS TRABAJADORES AGRÍCOLAS}

En los apartados anteriores nos centramos en la relación entre las formas de organización del trabajo y la conformación de los espacios físicos que las sustentan. Ahora nos centraremos en la subjetividad (espacio vivido) y prácticas (espacio percibido) de los trabajadores agrícolas en torno a su espacio de vida (Lefebvre, 2013). Es decir, nos enfocaremos en las prácticas específicas que tienden a modificar los espacios frecuentados y recorridos por estos sujetos (Lindón, 2002); como así también en los significados (percepciones, recuerdos, proyecciones, imaginarios, etc.) que se depositan sobre estos espacios. Como ya vimos al principio, las prácticas laborales (y al mismo tiempo espaciales) de los trabajadores son parte constitutiva de la reproducción del capital, pero no por ello quedan subordinadas de forma monolítica a las relaciones de poder que subyacen a una sociedad capitalista, mucho menos su subjetividad (Mitchell, 1996). Así, en tanto espacio de vida configurado históricamente, difiere de las visiones del paisaje promocionadas por los emprendimientos turísticos. Torres, Pastor, Grosso y Scoones (2018) señalan que las experiencias de turismo de lujo en el Valle de Uco, tienden a mercantilizar el paisaje y la naturaleza transformándolo en productos de consumo diferenciado. Y de este modo, como proceso anexo "se favorece la petrificación de las relaciones sociales y se las exime de conflictos" (p. 25).

La instalación de las empresas de la nueva vitivinicultura generó y aceleró una multiplicidad de dinámicas sociales. El paso de una residencia en una finca hacia una aglomeración de tipo urbana transformó considerablemente la vida cotidiana de los trabajadores agrícolas. La residencia en los pequeños lotes de las nuevas barriadas obreras limitó la capacidad de producción para el autoconsumo, la cual históricamente constituyó un complemento considerable del ingreso de los trabajadores agrícolas. Un entrevistado de un barrio de San Carlos comentó:

En la finca usted tenía lugar para criar un animalito, un chanchito para carnear en el invierno, que una ovejita, que unas gallinas, hasta cien gallinas he tenido (...) y ahora no, estoy aquí, ¿qué siembro? Sí tengo para poner un poquito de leña ahí atrás y listo. Y ahora aquí no tengo una gallina. (E3, obrero agrícola, 70-75 años)

Sin embargo, la desaparición de estas prácticas tampoco fue una cuestión de elección, ni ocurrió de forma automática. A medida que los barrios y caseríos comenzaron a densificarse, los problemas de convivencia motivaron la prohibición de la crianza de animales. Es decir, solo la intervención municipal puso fin a una práctica que había persistido a pesar del cambio del lugar de residencia. Una trabajadora que vivió toda su vida en Cordón del Plata relató:

La misma municipalidad ya empezó a prohibir los chiqueros, por ejemplo porque todos en ese lado tenían chiqueros. Eso tiene que haber sido en el ochenta y algo, noventa (...) Ya no podías tener animales, y las huertas tampoco. Por un tema del agua, porque ya empezó a escasear el agua y no se podía regar. (E8, obrera agrícola, 35-40 años)

La ruptura de lo que Poblete (2012, p. 2) Ilama la "unidad casa/trabajo" que había caracterizado al empleo permanente en la agricultura mendocina, implicó un cambio en las relaciones sociales laborales. Si bien, por un lado significó la pérdida de un vínculo laboral que garantizaba una residencia para el trabajador, por otro lado propició condiciones que son apreciadas o son vistas como un factor favorable por los trabajadores. En general, la mayoría destaca la mayor facilidad para conseguir empleo en estos barrios, debido al importante incremento de la demanda de trabajo temporario descripta en el apartado anterior. 
A nosotros nos facilitaba porque te ponen el transporte para llevarte a trabajary volver. Antes nosotros en la zona rural, lo que hacíamos para salir a laburar, si yo estaba acá tenía que ir caminando allá, allá, o allá. Ir caminando un par de kilómetros para ir a trabajar o ir en bicicleta. (E9, obrero agrícola, 25-30 años)

Esta situación de reducción de la dependencia de vínculos personales del empleo agropecuario ha llevado a que algunos trabajadores destaquen como positivo salir de las obligaciones que generaba el modelo anterior. Es decir, las obligaciones que siente el trabajador más allá del vínculo contractual, surgidas del hecho de residir en una casa prestada. Un trabajador mencionó: "La diferencia es que yo acá estoy en lo mío, no me molesta nadie. Si quiero ir a trabajar voy, no le tengo que pedir permiso a nadie. En una finca ya estás comprometido... tiene como más obligación de cumplir" (E6, obrero agrícola, 45-50 años).

El proceso de expulsión de población de las explotaciones, ya fueran productores o trabajadores, tampoco ocurrió de manera planificada y tuvo que ser resuelta sobre la marcha de manera individual o en el mejor de los casos de forma asociada entre vecinos. La localidad de Villa Seca del Departamento de Tunuyán es representativa de una urbanización que creció de forma espontánea a medida que fue aumentando su población (Fotografía 1). El pueblo estuvo durante mucho tiempo ligado a la actividad ganadera. Incluso hacia fines de la década de 1950, Inchauspe (1957) destacaba la vocación ganadera de los pueblos del oeste de Tupungato como Los Sauces y Villa Seca, principalmente dedicados a la cría de ganado ovino, caprino y en menor medida bovino. A partir de la segunda mitad del siglo XX, con el auge de la extracción de agua subterránea, la zona experimentó un crecimiento de explotaciones agrícolas de tamaño intermedio. Si bien creció la población en la zona, la mayoría se asentó en las nuevas fincas sin que ocurriesen grandes cambios en el pueblo. No fue sino hasta la instalación de las nuevas bodegas en el piedemonte que Villa Seca tuvo un crecimiento considerable y repentino.

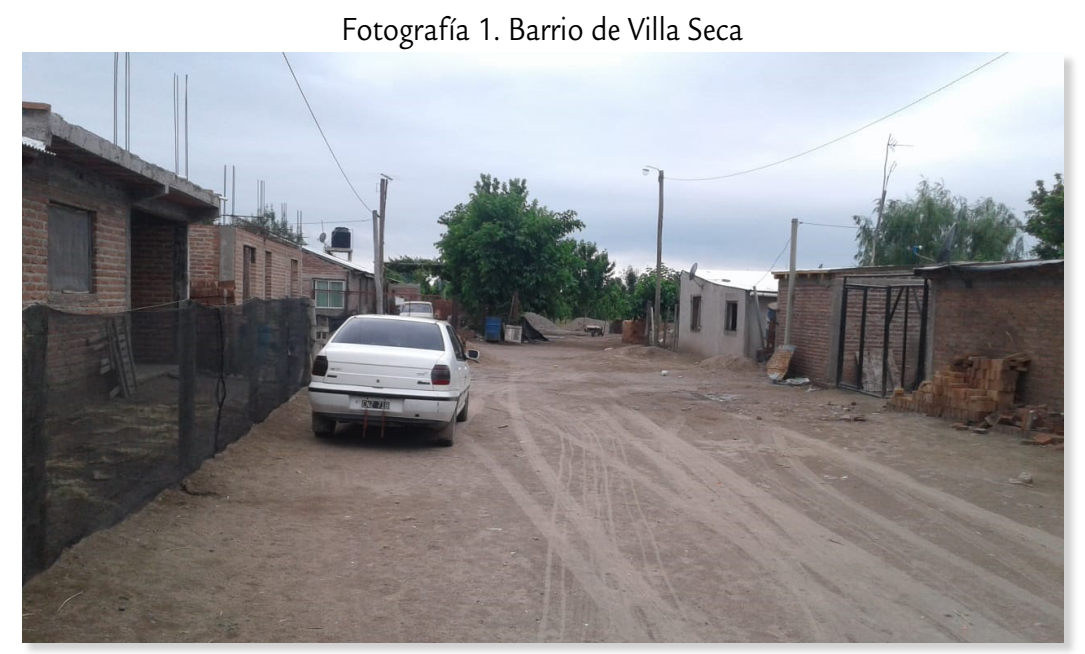

Fuente: archivo de los autores

El pueblo creció a medida que sus habitantes fueron levantando sus propias casas. Un poblador del barrio comentó

Hace 12 años que estoy y habían dos o tres casas nomás y ahí han empezado a construir todo (...) esto era un lote, era un campo, y ahí lotearon para vender (...) cada quien compraba su terreno y se iba haciendo la casa. (E6, obrero agrícola, 45-50 años)

La única organización vecinal está destinada a garantizar la provisión de agua, lo cual en los últimos años se ha tornado una tarea complicada debido al aumento de la 
población. "Están peleando a ver si se puede hacer un pozo más, un tanque más porque es poca el agua (...) antes eran 30 cuando se hizo la unión vecinal para el agua y ahora hay 130 usuarios o mucho más" (E10, obrera agrícola, 40-45 años).

Actualmente buena parte de sus habitantes permanentes provienen de provincias del norte argentino y de Bolivia. Además en temporada de cosecha arriban a los barrios cantidades importantes de trabajadores temporarios, entre los que destacan tucumanos, salteños y jujeños. Una trabajadora agrícola comentó:

De la zona todos trabajan en la tierra (... la mayoría son cuadrilleros, llevan gente van a trabajar así, a la uva, al durazno, a la cereza (...) Ahí (señala una casa) viene gente ya de años y él tiene sus piecitas para su gente, vienen en temporada. Ellos ponele que son jujeños, salteños. Mendocinos es poco lo que hay (risas). (E10 obrera agrícola, 40-45 años)

A diferencia de Villa Seca, el pueblo de Cordón del Plata en el departamento de Tupungato combina una urbanización surgida de una organización vecinal con el soporte de organismos estatales y otros sectores del barrio surgidos de una urbanización espontánea. Esta situación fue característica del auge de la descentralización de organismos estatales de la década de 1990, del cual las instituciones encargadas de la construcción de viviendas no fueron ajenas. Organismos como el IPV (Instituto Provincial de la Vivienda) sufrieron una reducción en su estructura y funciones, las cuales se transfirieron a otros actores de la sociedad (IPV, 2007). Parte de la planificación entonces recayó en los mismos destinatarios, quienes debían nuclearse en cooperativas y uniones vecinales para presentar sus planes a los municipios. Este proceso, si bien proponía la autogestión y una mayor participación de las comunidades, ocasionó serias falencias producto de la retirada del Estado un su papel planificador; entre las cuales cabe mencionar un "excesivo alargamiento de los plazos de obra que llegaron en muchos casos a una virtual paralización, con la calidad de las obras, con el desempeño irregular de algunas entidades por falta de control" (IPV, 2007, p. 58). En muchos casos se terminó privilegiando el bajo costo de los terrenos, provocando una ocupación discontinua del espacio sobre suelos agrícolas especulando con la posterior provisión de servicios urbanos.

Cordón del Plata fue una de las localidades de mayor crecimiento en la provincia en las últimas tres décadas. La mayoría de sus habitantes son trabajadores rurales, aparceros o trabajan en la agroindustria asentada en la localidad. La historia del pueblo es inseparable de la organización y de las continuas luchas de sus habitantes buscando mejorar sus condiciones de vida. Una de sus habitantes rememorando sobre su infancia a principios de la década de 1970 relató:

Vivía sobre la ruta, que era lo único que había antes en el Cordón (...) estaba la escuela vieja, la Antártida Argentina, jescuela rancho! (...) no teníamos luz, la calle era de tierra. La calle, esta ruta era un callejón (...) eran poquitos, si eran diez vecinos y eso era todo lo que había en el Cordón. (E8, obrera agrícola, 35-40 años)

Los reclamos en ese entonces corrían por cuenta de un puñado de vecinos que llevaban sus inquietudes al intendente. Los mismos tenían por objeto temas como el ingreso del transporte público al caserío, mejoras en la escuela o por la llegada del tendido eléctrico. En 1976 se instaló en el pueblo una pequeña agroindustria, la cual fue creciendo hasta llegar a ocupar cerca de 300 personas en plena temporada.

Hacia la década de 1980 el pueblo ya mostraba una dinámica de crecimiento importante. Para ese entonces algunos vecinos organizaron una cooperativa con el objetivo de impulsar la construcción de un barrio. "Habrá empezado en el '85 (...) Todos los que trabajaron ahí eran del pueblo. Todos se hicieron albañiles, electricistas. La misma gente de acá, fue una empresa 
que se yo, pero los obreros eran todos de acá" (E8, obrera agrícola, 35-40 años). El pueblo se fue expandiendo en varias etapas. Inicialmente se hicieron cinco manzanas, denominado $\mathrm{B}^{\circ}$ Cordón del Plata, luego cinco manzanas más llamado $\mathrm{B}^{\circ}$ Los Álamos y luego cuatro más que forman el $\mathrm{B}^{\circ}$ Norte. Estos barrios se entregaron entre fines de la década de 1980 y principios de la década del 2000, todos construidos bajo planes del IPV.

Las dificultades aparecieron incluso antes de comenzar. Algunos entrevistados levantaron críticas al manejo de la cooperativa. Entre ellas se mencionan el pago por duplicado de los terrenos que tuvieron que efectuar algunos vecinos a la cooperativa, la primera cuando se compra el terreno total del barrio y luego nuevamente para la compra de los lotes individuales. "Se tuvo que volver a comprar lo que ya se había comprado. Se quedaron (los que manejaban la cooperativa) con la plata de este, con la plata de aquel, porque eso se había pagado todo" (E8 obrera agrícola, 35-40 años). La etapa de construcción también tuvo que sortear dificultades que luego terminarían condicionando la habitabilidad de las viviendas.

Empezaron y se quedó ahí, se murió durante muchos años, como dos años. Estaban medio construidas. Me acuerdo que los caños estaban a la intemperie, se quemaron con el sol y las heladas (...) yo esperaba otra cosa. No te digo ;Oh! (algo de gran calidad) pero hubiese estado construido de otra manera, no tan feo el plano porque es horrible. Y esto al poquito andar se partieron las paredes (E8, obrera agrícola, 35-40 años)

Irregularidades similares surgieron en la etapa siguiente de construcción del barrio hacia el este, cuya construcción ya fue encarada de manera individual por sus habitantes (Fotografía 2).

Se llama loteo Bazán, que es una señora que compró y entró a vender, como que vendió todo urbanizado, y les hizo un cuento a los compradores, y no hay nada. Entonces empezaron a reclamar los terrenos y se los dio así nomás, y encima no tienen luz para cada casa, tienen un solo medidor. Tienen un transformador que puede abastecer 50 casas y hay 150 (...) Es gente de acá, y gente del norte, de Jujuy, Salta y hay mucha gente de Bolivia. (E7, obrero agrícola, 20-25 años)

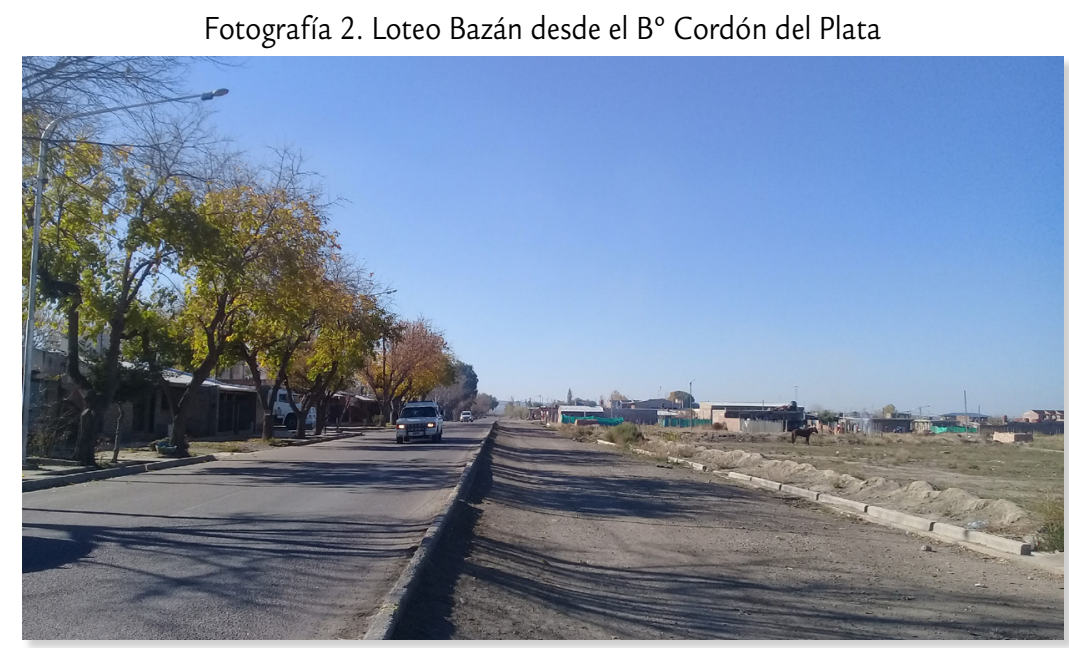

Fuente: archivos de los autores

El rápido y desorganizado crecimiento que sobrevino en Cordón del Plata desde inicios de siglo generó numerosas tensiones sociales. Los conflictos se desataron principalmente por el suministro de agua y la atención sanitaria. Recientemente se produjo una pueblada por problemas de inseguridad, que deja entrever numerosos reclamos por discriminación hacia la comunidad boliviana. Un entrevistado del pueblo recuerda: 
Entonces lo que pasaba era que faltaba agua, la sala (centro de salud) no daba abasto, en realidad no dio nunca abasto pero había momento donde se generaba mucho conflicto en el ingreso concreto (...) Se juntaban más que nada afuera de la escuela y empezaban a charlar de todos los problemas que tenían y alguno proponía algo. Y bueno, generalmente los cortes los hicieron todos afuera de la escuela primaria, y después empezaron a hacerlo... hay un cruce en la fábrica de Cordón del Plata, que está la fábrica ALCO y la entrada por el lado este, entonces cortaban esos dos puntos. (E9, obrero agrícola, 25-30 años)

Esta descripción presenta de manera vívida los espacios que se constituyen como la trastienda de los espléndidos paisajes promocionados por la nueva vitivinicultura, sin los cuales estos últimos no serían posibles. En este punto resulta pertinente rescatar una reflexión de Walker (2004) sobre la vista modesta o incluso empobrecida de los pueblos rurales de California, en contraste con la riqueza que genera su agricultura. Allí propone que esto se debe a la falta de una clase farmer (productores familiares capitalizados) que densifique los circuitos locales de comercio y de reproducción social, como los que presenta el medio oeste de los EEUU. Tomando referencias más cercanas podemos pensar en los pueblos rurales de la pampa húmeda a mediados de la década de 1960 o incluso en la vitivinicultura mendocina del mismo periodo. En su lugar Walker señala un capital que tiene su base lejos y de forma ajena a estos territorios.

De allí derivan numerosas trayectorias y percepciones sobre el paisaje por parte de sus habitantes, las cuales se oponen a las instituidas por los emprendimientos vitivinícolas, en tanto experiencias empaquetadas y creadas para ser apreciadas de una determinada manera. A nuestro entender aquí no logra operar la mistificación de estas representaciones del paisaje, sino que refuerzan la percepción de desigualdad. De nuestro trabajo de campo podemos ver que en lo que se refiere a las percepciones del espacio (espacio vivido), de los trabajadores y sus familias poseen múltiples matices y están asociados a su trayectoria personal en el espacio. Consultados sobre la apreciación de los entornos paisajísticos emblemáticos para el turismo en la región surgieron respuestas como: "En los espacios de turismo ves las fotitos todas armadas. Yo cuando estaba en el viñedo no miraba la montaña, estaba preocupado en cuantas hileras me hacía". (E9, obrero agrícola, 25-30 años)

Yo trabajando en el Clos de los Siete, primero que vas con los que te llevan que te pagan una miseria (...) sabíamos estar en la viña e iban en el cuatri los turistas, o a caballo o en bicicleta. Una calor, nosotras tapadas, cubiertas, y las chicas en bicicleta cuesta arriba por ese pedregal en los callejones. Digo yo "miércoles, yo las pondría acá que me hicieran una hilerita, vamos a ver si les parece tan bonito este sol” (...) habrá pagado tres veces más de lo que me están pagando a mí. (E8, obrera agrícola, 35-40 años)

Por otro lado, como señala Mitchell (1996) si bien el paisaje de alguna manera representa una ideología visual que se expresa en una arquitectura y disposición espacial de clase, de género y racializada, también es cierto que "el paisaje no es un simple reflejo de las necesidades y deseos de las clases dominantes” (p. 31). Ya que a menudo las clases subordinadas generan, consciente o inconscientemente, concepciones alternativas de paisaje. Como nos señaló un trabajador rural:

esta gente que vive en Cordón del Plata, que son nuestros vecinos, el lugar de dispersión que ellos van a elegir va a ser la feria, me parece a mí, va a ser ese lugar que funciona viernes, sábado y domingo (...) esa sería para míla fotografía de la percepción del pueblo cordonino, de los de abajo digamos. (E9, obrero agrícola, 25-30 años)

La feria como lugar de dispersión, de socialización, además de una fuente de ingreso es quizás un paisaje propio de las clases populares. Pero también otros ámbitos son valorados como espacios de socialización que convocan a jóvenes y que componen los lugares de principal interés. Una obrera del Cordón relató: "lo que pasa es que acá hay muchos ballet por ejemplo, de folklore, de saya, impresionante hay montones y junta muchos chicos eso (...) los 
paisanos se han volcado al folklore y los... (risas) sí al revés..." (E8, obrera agrícola, 35-40 años). El paisaje asociado a la vida, a las formas de socializar y de crear y recrear identidad se contrapone a las experiencias de los espacios consumibles comentados por Torres et al. (2018) en su análisis del turismo de lujo (Fotografías 3 y 4). El paisaje propuesto por estas percepciones implica un espacio donde se liman asperezas culturales, y por ello, más igualitario; y a su vez paisajes multiculturales y comunitarios donde las experiencias escapan a la mera mercantilización y consumo y tienden a la socialización de los pobladores.

En la Fotografía 3 se observa la comunidad del Cordón del Plata congregada para la séptima edición de la Vendimia Obrera que incluye al trabajador rural como parte central de la celebración popular. En la Fotografía 4 se observa el típico escenario de viñedos con la Cordillera de los Andes de fondo con la que se promociona al Valle de Uco como uno de los mejores destinos para ir en el 2020 según la revista National Geographic.

Fotografía 3 y 4. Paisajes para la vida versus paisajes de exportación
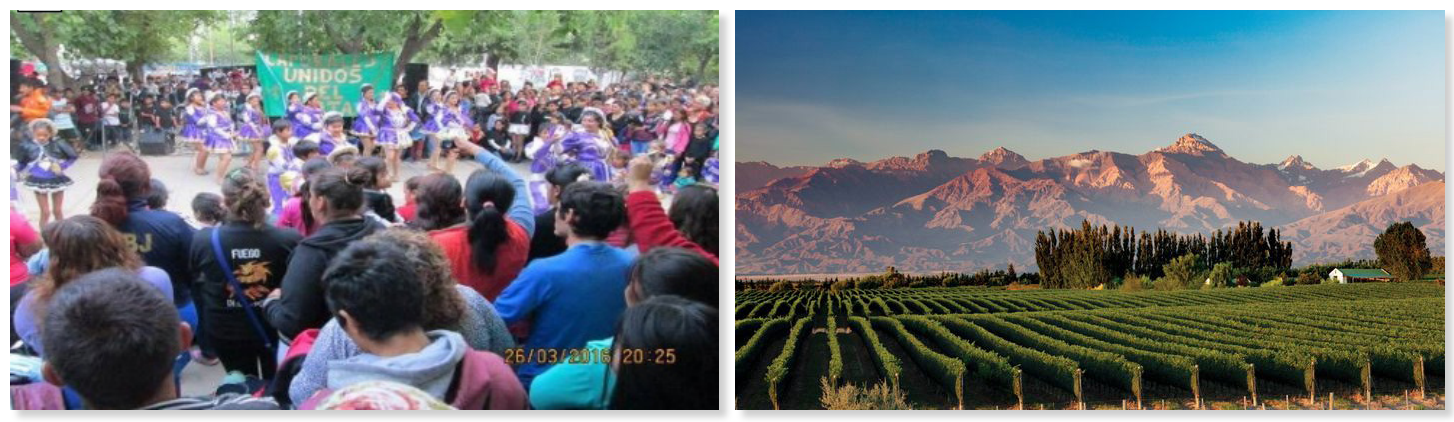

Fuente: El Cuco Digital (5-4-2016) y National Geographic (20-11-2019)

\section{CONCLUSIONES}

Esta investigación busca problematizar los paisajes vitivinícolas del Valle de Uco, promocionados con imágenes de lujo en las que lucen verdes hileras de vides con la Cordillera de los Andes coronando la escena. Para ello nos propusimos abordar en aquello que no es tan aparente en dicha fotografía, más específicamente en la trastienda que hace posible la existencia de ese paisaje. Trastienda y paisaje resultan inseparables y forman parte del mismo proceso de construcción del espacio. Pero no se trata de un proceso unidireccional determinado por los deseos del capital y sus planificadores, al mismo tiempo la lucha cotidiana de los trabajadores por sus condiciones de existencia contribuye a crear la morfología de ese paisaje.

El modelo de la nueva vitivinicultura implicó una nueva forma de organización del trabajo que rompió con otra forma histórica basada en la residencia de los trabajadores en la explotación. La distribución y morfología de los nuevos barrios obreros está en estrecha relación con el proceso de concentración de la producción agrícola, que implicó, por un lado, la instalación de grandes emprendimientos y, por otro, su contracara, el proceso de abandono y desaparición de pequeñas explotaciones. Estos barrios dieron respuesta a las nuevas demandas laborales de las grandes empresas y en muchos casos se convirtieron es espacios de articulación del mercado de trabajo. Pero también la historia de la construcción de los mismos ilustra las diversas estrategias y obstáculos que debieron enfrentar los trabajadores para erigir sus espacios de vida. Si bien las mismas están plagadas de inconvenientes, también alumbraron procesos comunitarios espontáneos y organizados que redefinieron sus percepciones y prácticas individuales y colectivas. 
El análisis del trabajo de campo nos permite apreciar, además, diversas percepciones del paisaje entre los trabajadores, que resultan inseparables de sus trayectorias personales. Estas percepciones en ocasiones contrastan y resisten a las difundidas por los emprendimientos vitivinícolas. La tensión entre la ideología visual del paisaje propuesta por los emprendimientos turísticos y las percepciones que los trabajadores y las trabajadoras se forman en su lucha cotidiana por lograr sus espacios de vida refuerzan la percepción de desigualdad. Los paisajes elegidos para disfrutar y vivir por los trabajadores difieren de los que ellos mismos producen con su actividad laboral. Sus paisajes se caracterizan por ser espacios de socialización, entretenimiento y de intercambio. Las ferias, festividades comunales, los ballets populares, etc., se alejan de las experiencias evocativas y sibaritas propuestas por el circuito turístico. Por el contrario apelan a la sociabilidad cotidiana y a prácticas culturales de diálogo y encuentro comunal. La trastienda, como metáfora de estas potentes dinámicas de crecimiento de los barrios de manera desordenada y abrupta, nos ilustra sobre un proceso material que permite observar, de modo muy explícito, las tensiones entre el capital y el trabajo.

\section{REFERENCIAS}

Antunes, R. (2013). Los sentidos del trabajo. Ensayo sobre la afirmación y la negación del trabajo. Herramienta ediciones.

Aparicio, S. y Benencia, R. (1999). Empleo Rural en la Argentina. Viejos y nuevos actores sociales en el mercado de trabajo (pp. 29-81). En S. Aparicio y R. Benencia (Coords.) Empleo Rural en tiempos de flexibilidad. Buenos Aires: La Colmena.

Baringo Ezquerra, D. (2013). La tesis de la producción del espacio en Henri Lefebvre y sus críticos: un enfoque a tomar en consideración. Quid, 16(3), 119-135

Bragoni, B. (2004). La Mendoza criolla. Economía, sociedad y política (1820-1880) (pp. 135-181). En A. Roig, P. Lacoste y M. Satiari (Comps.) Mendoza a través de su historia. Mendoza: Colección Cono Sur.

Carballo, O. (2019). Concentración y resistencias en la producción hortícola del Oasis Norte y Centro de Mendoza. Argentina. Tesis Doctoral. Doctorado en Estudios Sociales Agrarios. Universidad Nacional de Córdoba.

Carballo, O. e Ivars, J. (2018). Subsunción formal de formas de organización de trabajo recíprocas: el caso de las "turnas" en la horticultura de Mendoza en Argentina. Boletín Científico Sapiens Research, 8(1), 71-83

Collado, P. (2006). Desarrollo vitivinícola en Mendoza-Argentina. Apuntes sobre su origen. Trabajo y sociedad, VII(8). Recuperado de www.unse.edu.ar/trabajoysociedad/Collado.pdf

De la Garza, E. (1993). Reestructuración productiva y respuesta sindical en México. México: IIEUNAM.

De la Garza, E. (2011). Trabajo atípico: Identidad o Fragmentación. Alternativas de análisis (pp. 49-76). En E. Pacheco, E. De la Garza y L. Reygadas (Orgs.) Trabajos atípicos y precarización del empleo. México: COLMEX.

Delgado, G. (2004). Mendoza y el ferrocarril (pp. 183-208). En A. Roig, P. Lacoste y M. Satiari (Comps.) Mendoza a través de su historia. Mendoza: Colección Cono Sur.

Delgado, M. (2013). El espacio público como representación. Espacio urbano y espacio social en Henri Lefebvre. Recuperado de http://www.oasrn.org/pdf_upload/el_espacio_publico.pdf. 
Dirección Agropecuaria DA (1979). Censo Agropecuario del Valle de Uco. Año 1979.

Dirección Nacional del Servicio Estadístico DNSE (1947). IV Censo General de la Nación. Recuperado de http://deie.mendoza.gov.ar/\#!/censos-nacionales-de-poblacion/1947-cuarto-censo-general-de-la-nacion-42

El Cuco Digital (5-4-2016). La séptima edición de la vendimia obrera lleno la plaza del Cordón del Plata. Recuperado de https://www.elcucodigital.com/la-septima-edicion-de-la-vendimia-obrera-lleno-la-plaza-del-cordon-del-plata/

Fabio, J. (2006). El trabajo estacional en la agricultura. Tipos de trabajadores y estrategias laborales en la provincia de Mendoza. VII Congreso Latinoamericano de Sociología Rural (ALASRU).

Fili, J. y Engelman, A. (2020). Litigios en torno al dominio público y privado de las aguas en el Valle de Uco, Mendoza (Argentina) a finales del siglo XIX. Revista Anuario de Historia Regional y de las Fronteras, 25(1), 47-68

Furlani, M.; Gutiérrez, M.; Molina, G. y Lotfi, V. (2000). Producción de lo urbano en un área de oasis. Mundo Urbano, (5).

Giarracca, N. y Teubal, M. (2017). Del desarrollo agroindustrial a la expansión del "agronegocio": el caso argentino. En N. Giarracca Estudios rurales y movimientos sociales: miradas desde el Sur. Antología esencial. Buenos Aires: CLACSO

Inchauspe, O. (1957). La cuenca superior y media del Río Tunuyán. Boletín de Estudios Geográficos, (16), 131-145.

Instituto de Desarrollo Rural IDR (2018). Actualización de la superficie de Pera y Manzana. Zona Valle de Uco - Mendoza. Recuperado de https://www.idr.org.ar/wp-content/ uploads/2018/05/Actualizaci\%c3\%b3n-de-la-Sup.-de-Pera-y-Manzana.pdf

Instituto de Investigaciones Económicas y Tecnológicas IIET (1962). Censo Nacional Agropecuario 1960. Resultados provisorios obtenidos de la compilación efectuada para Mendoza por el I.E.T. Ministerio de economía, obras públicas y riego

Instituto Nacional de Estadística y Censos INDEC (1988). Censo Nacional Agropecuario.

Instituto Nacional de Estadística y Censos INDEC (2001). Censo Nacional de Población, Hogares y Viviendas.

Instituto Nacional de Estadística y Censos INDEC (2002). Censo Nacional Agropecuario. Instituto Nacional de Estadística y Censos INDEC (2008). Censo Nacional Agropecuario.

Instituto Nacional de Estadística y Censos INDEC (2010). Censo Nacional de Población, Hogares y Viviendas.

Instituto Provincial de la Vivienda IPV (2007). 60 años de historia. 1947-2007. Instituto Provincial de la Vivienda. Gobierno de Mendoza

Kay, C. (1997). Latin America's exclusionary rural development in a neo-liberal world. Reunión del Latin American Studies Association (LASA). Guadalajara, Mexico.

Lacoste, P. (1997). Mendoza. Historia y perspectivas. Aportes para el estudio de una ciudad fundada en 1561. Mendoza: Diario Uno-Universidad de Congreso.

Lara, S. (1992). La flexibilidad del mercado de trabajo rural (una propuesta que involucra a las mujeres). Revista Mexicana de Sociología, 54(1), 29-48

Larsimont, R. (2018). Modelo de Agronegocio, Agua y Ruralidad en los oasis de Mendoza, 19902017: hacia una Ecología Política Territorial. Tesis Doctoral. Universidad de Buenos Aires Lefebvre, H. (2013). La producción del espacio. España: Gracel Asociados. 
Lindón, A. (2002). Trabajo, espacios de vida y cotidianidad. La periferia oriental de la ciudad de México. Scripta Nova, 6(119).

Martínez, M.; de la Rosa, E.; Suortino, R.; Gómez, G. y Castro, P. (1999). Dinámica del crecimiento de áreas residenciales urbanas y rurales del Valle de Uco. Actuales formas de planificación del desarrollo rural (pp. 99-114). En M.E. Furlani y M.J. Gutiérrez (Coords.) Mendoza: una geografía en transformación. Segunda Parte. Mendoza: Editorial de la Facultad de Filosofía y Letras de la Universidad Nacional de Cuyo

Ministerio del Interior MI (1869). Primer Censo de la Nación Argentina. Año 1869. Recuperado de http://deie.mendoza.gov.ar/\#!/censos-nacionales-de-poblacion/1869-primer-censo-de-la-nacion-argentina-17

Mitchell, D. (1996). The lie of the land: migrant workers and the California landscape. Minneapolis: University of Minnesota Press

Molina, G. (1999). Capacidad de los centros urbanos de Valle de Uco para absorber población (pp.77-86). En M.E. Furlani y M.J. Gutiérrez (Coords.) Mendoza: una geografía en transformación. Segunda Parte. Mendoza: Editorial de la Facultad de Filosofía y Letras de la Universidad Nacional de Cuyo

Montaña, E. (2008). Las disputas territoriales de una sociedad hídrica: conflictos en torno al agua en Mendoza, Argentina. Revista Iberoamericana de Economía Ecológica, (9), 1-17.

Moreno, M. (2019). Territorialidad inmigratoria de trabajadores bolivianos en Mendoza (Argentina). Aproximación etnográfica a partir de tres casos de estudio emplazados en espacios rurales. Territorios, (41), 23-43.

National Geographic (20-11-2019). Los mejores viajes para haceren 2020. Recuperado de https:// www.nationalgeographicla.com/viajes/2019/11/los-mejores-viajes-para-hacer-en-2020

Neiman, G. (2010). Los estudios sobre el trabajo agrario en la última década: una revisión para el caso argentino. Mundo Agrario, 10(20).

Neiman, G.; Bardomas, S. y Quaranta, G. (2003). El trabajo en el agro pampeano. Análisis de la demanda de trabajadores asalariados. Revista Interdisciplinaria de Estudios Agrarios, (19).

Poblete, L. (2012). De trabajadores inamovibles a trabajadores móviles. El caso de los contratistas de una región vitícola de Mendoza, Argentina. Cuadernos de Relaciones Laborales, 30(2).

Pol, M.; Fresia, A.; Romero, S. (2015). Estructura productiva y dinámica migratoria en la Provincia de Mendoza. 1860-2010. Estudios sociales contemporáneos, (13), 151-171

Rau, V. (2009). La situación de los trabajadores agropecuarios transitorios en la Argentina. XXVII Congreso de la Asociación de Sociología.

Richard-Jorba, R. (1998). Poder, economía y espacio en Mendoza, 1850-1900: del comercio ganadero a la agroindustria vitivinícola. Mendoza: Editorial de la Facultad de Filosofía y Letras. UNCuyo.

Richard-Jorba, R. (2000). El mercado de trabajo rural en Mendoza. Un panorama sobre su formación y funcionamiento entre la segunda mitad del siglo XIX y comienzos del XX. Población \& Sociedad, (8-9), 211-267

Richard-Jorba, R. (2008). Crisis y transformaciones recientes en la región vitivinícola argentina. Mendoza y San Juan, 1970-2005. Estudios Sociales, 16(31), 82-123

Roncelli, I. (1969). Expansión actual del Oasis de Tupungato: La conquista del suelo en la zona baja. Boletín de Estudios Geográficos, (63), 67-102

Rubio, B. (2001). Explotados y excluidos. México: Plaza y Valdés. 
Sabalain, C. y Reboratti, C. (1980). Vendimia, zafra y alzada: migraciones estacionales en Argentina. Cuaderno del CENEP, (15).

Saldi, L. y Petz, I. (2015). Aguas ajenas, tierras extrañas. Desigualdad hídrica al sur de la cordillera de los Andes en Mendoza (Argentina) a principios del siglo XXI. Cuadernos de Desarrollo Rural, 12(75), 123-144. DOI http://dx.doi.org/10.11144/Javeriana.cdr12-75.aate

Salvatore, R. (1986). Control del trabajo y discriminación: el sistema de contratistas en Mendoza, Argentina, 1880-1920. Desarrollo Económico, 26(102), 229-253

Thomaz Júnior, A. (2002). Por uma Geografia do Trabalho. Pegada, 3. Número Especial agosto.

Torres, L.; Pastor, G.; Grosso, M. y Scoones, A. (2018). Turismo de lujo y extractivismo: la ruralidad como presa del capital. Reflexiones a propósito del Valle de Uco (Argentina). Scripta Nova, XXII(585). Recuperado de http://revistes.ub.edu/index.php/ScriptaNova/article/view/19210

Van den Bosch, M. (2008a). Zonas Agroeconómicas Homogéneas. San Juan y Mendoza. Estudios económicos de los sistemas productivos y recursos naturales, (4).

Van den Bosch, M. (2008b). Un modelo de desarrollo sustentable en las áreas bajo riego de los distritos Ugarteche y El Carrizal. Departamento de Luján de Cuyo. Provincia de Mendoza: un aporte para el ordenamiento territorial rural. Tesis de maestría. Universidad Nacional de Cuyo

Velasco, M. (1963). La horticultura en Mendoza. La técnica agrícola, la estructura agraria y el valor económico de las hortalizas. Boletín de Estudios Geográficos, (39), 41-89

Walker, R. (2004). The Conquest of Bread: 150 Years of Agribusiness in California. New York: The New Press.

\section{ENTREVISTAS}

E1: Ingeniero agrónomo de INTA. Hombre. Edad: 55-60 años. San Carlos (enero, 2012)

E2: Encargado de finca. Hombre. Edad: 35-40 años. Tupungato (agosto, 2017)

E3: Obrero agrícola, ex-aparcero hortícola. Hombre. Edad: 70-75 años. San Carlos (enero, 2012)

E4: Productor mediano (finca de 55 ha). Hombre. Edad: 29 años. San Carlos (enero, 2012)

E5: Obrero rural. Hombre. Edad: 20-25 años. B ${ }^{\circ}$ El Esfuerzo. San Carlos (agosto, 2012)

E6: Obrero rural. Hombre. Edad: 45-50 años. Villa Seca. Tunuyán (diciembre, 2017)

E7: Obrero rural. Hombre. Edad: 20-25 años. Cordón del Plata. Tupungato (agosto, 2012)

E8: Obrera rural. Mujer. Edad: 35-40 años. Cordón del Plata. Tupungato (junio, 2018)

E9: Obrero Rural .Hombre. Edad: 25-30 años. Cordón del Plata. Tupungato (junio, 2018)

E10: Obrera rural. Mujer. 40-45 años. Villa Seca. Tunuyán (diciembre, 2017)

Oscar Carballo es Licenciado en Sociología. Doctor en Estudios Sociales Agrarios. Becario Posdoctoral del Consejo Nacional de Investigaciones Científicas y Técnicas CONICET. Sus temas de investigación son Desarrollo territorial rural. Instituto de Ciencias Humanas, Sociales y Ambientales INCIHUSA. Centro Científico Tecnológico CONICET Mendoza. Av. Ruiz Leal s/n Parque General San Martín, (5500) Mendoza, Argentina, oscar24oac@gmail.com, ORCID https://orcid.org/0000-0002-4407-6221 
Juan Pablo Fili es Licenciado en Sociología (Universidad Nacional de Cuyo). Becario doctoral del Consejo Nacional de Investigaciones Científicas y Técnicas CONICET. Candidato a doctor en Estudios Sociales Agrarios (Centro de Estudios Avanzados, Universidad Nacional de Córdoba). Sus temas de investigación son Economía Política de la Agricultura. Departamento de Geografía. Facultad de Filosofía y Letras. Universidad Nacional de Cuyo. Centro Universitario, Parque San Martín s/n, (5502) Mendoza, Argentina, juanpablo_fili@yahoo.com, ORCID https://orcid.org/0000-0001-7672-3772

Anabela Ayelén Engelman es Geógrafa Profesional (Universidad Nacional de Cuyo). Becaria doctoral del Consejo Nacional de Investigaciones Científicas y Técnicas CONICET. Candidata a doctora en Ciencias Sociales (Facultad de Ciencias Políticas y Sociales, Universidad Nacional de Cuyo). Instituto de Ciencias Humanas, Sociales y Ambientales INCIHUSA. Centro Científico Tecnológico CONICET Mendoza. Av. Ruiz Leal s/n Parque General San Martín, (5500) Mendoza, Argentina, anabellaengelman@gmail.com, ORCID https://orcid.org/0000-0002-0718-2762 